\title{
Health care transition for patients with vascular malformations: a French multicenter cross-sectional study
}

\author{
Camille Vermersch ${ }^{1}$, Olivia Boccara ${ }^{2,3}$, Christine Chiaverini ${ }^{4}$, Juliette Mazereeuw-Hautier ${ }^{5}$, Nina Sigg ${ }^{6}$, \\ Stéphanie Mallet ${ }^{7}$, Pierre Vabres ${ }^{8}$, Denis Herbreteau ${ }^{9}$, Anne Le Touze ${ }^{10}$, Annabel Maruani ${ }^{1,11 \dagger}$, \\ Sophie Leducq ${ }^{1,11^{*}+}$ (D) and Research Group of the Société Française de Dermatologie Pédiatrique (French \\ Society of Pediatric Dermatology)
}

\begin{abstract}
Background: Health care transition (i.e., transition from pediatric to adult care) is challenging in chronic conditions but has been poorly studied in rare chronic skin diseases. We investigated the proportion of lost to follow-up among patients with superficial vascular malformations after health care transition. We also collected patients' opinions. This prospective, multicenter, cross-sectional study was performed at 7 French hospitals. We included patients aged 19-25 years, who were followed for a superficial vascular malformation before age 16, and who had completed the transition period in 2020. Data were collected from medical records and a questionnaire was sent to included patients asking about the health care transition.

Results: Among the 90 patients included, 41 (46\%) were lost to follow-up after health care transition period. The age at diagnosis was significantly higher for lost to follow-up than non- lost to follow-up patients. The lost to follow-up proportion was similar between patients who changed and did not change hospitals during the transition. Responses to the questionnaire were obtained for 47 of 90 patients (52.2\% response rate); most were satisfied with their care ( $n=31 / 36,86.1 \%)$; however, a lack of psychological support was reported.

Conclusions: Health care transition is associated to a high rate of lost to follow-up. Early management seems associated to less lost to follow-up. Further studies are needed to better understand risk factors for a failed health care transition and its consequences.
\end{abstract}

Keywords: Rare skin diseases, Health care transition, Patient transfer, Vascular malformations, Adult, Children, Survey, Patient satisfaction

*Correspondence: sophie.leducq@univ-tours.fr

${ }^{\dagger}$ Annabel Maruani and Sophie Leducq contributed equally to this work. ${ }^{1}$ Department of Dermatology and Reference Center for Rare Diseases and Vascular Malformations (MAGEC), CHRU Tours, Avenue de La République, 37044 Tours Cedex 9, France

Full list of author information is available at the end of the article

\section{Background}

Superficial vascular malformations (SVMs) are congenital rare conditions of children and adults, with a prevalence estimated at $1.2 \%$ [1]. In numerous types of SVMs, post-zygotic mutations in genes involved in vasculogenesis have been identified; the consequences are inborn errors in vascular morphogenesis $[2,3]$. SVMs are divided into four subtypes according to the vessels involved: capillary, lymphatic, venous original author(s) and the source, provide a link to the Creative Commons licence, and indicate if changes were made. The images or other third party material in this article are included in the article's Creative Commons licence, unless indicated otherwise in a credit line to the material. If material is not included in the article's Creative Commons licence and your intended use is not permitted by statutory regulation or exceeds the permitted use, you will need to obtain permission directly from the copyright holder. To view a copy of this licence, visit http://creativecommons.org/licenses/by/4.0/. The Creative Commons Public Domain Dedication waiver (http://creativeco mmons.org/publicdomain/zero/1.0/) applies to the data made available in this article, unless otherwise stated in a credit line to the data. 
and arteriovenous malformations, that can be isolated, combined, or associated with other anomalies [4]. Although SVMs are present at birth, they are not always apparent at this stage and might even manifest during adulthood [5]. The natural history of SVMs depends on the subtype and usually consists of progressive worsening during life which often leads to moderate to severe functional impairment and decreased quality of life [6-8]. Except for very small SVMs that have curative treatment, management of SVMs is a lifelong process that requires long-term follow-up during childhood and adulthood.

Adolescence is a complex period for management because it involves multiple transformations. Hormonal changes may worsen SVMs [6]; also, the adolescents' desire for independence might lead them to disrupt their treatment and follow-up, which also might induce disease worsening [9]. Finally, the health care systems, including caregivers, sometimes change during this transition period, depending on each country's health care organization [10]. For example, in France, pediatric hospitals and health care units usually see children until they reach 15 years and 3 months, then adolescents are cared for in adult departments. This transition from pediatric to adult care is called "health care transition" (HCT). HCT can be defined as "the process of moving from a pediatric to an adult model of health care with or without a transfer to a new health care provider" [11]. HCT for patients with a chronic disease requires providing "health care that is uninterrupted, coordinated, developmentally appropriate, psychosocially sound, and comprehensive" [12]. It has been described and analyzed in chronic pathologies such as HIV or diabetes [13, 14]. However, in rare diseases, $\mathrm{HCT}$ is all the more challenging as there is a strong relationship between the patient and the physician due to long-term follow-up, and also it may be difficult to find physicians with a good knowledge of the disease in adult departments. A recent literature review of HCT in 2020 highlighted practical considerations to facilitate the development of programs for epidermolysis bullosa and few other dermatologic conditions [15], still there are no published data on HCT in rare chronic conditions such as SVMs. Although they do not threaten life as for HIV or diabetes, a successful transition care is necessary to ensure regular appointments during adulthood for optimal management.

The objectives of this study were to (1) assess the prevalence of lost to follow-up (LFU) in patients with SVMs during HCT; (2) evaluate the impact of HCT on care consumption; (3) describe modalities of HCT in French centers and (4) describe patients' perception on HCT.

\section{Results}

Characteristics of study participants (Table 1)

A total of 90 patients were included (Fig. 1): 51

(56.7\%) women and 39 men (43.3\%). The median age was 21.0 years (interquartile range 20-22.25 [range 19-25 years]). All types of SVMs were represented, most being venous malformations (38 patients, $42.0 \%$ ). The most frequent location was the lower limb $(n=36$, $40.0 \%$ ). The median age at diagnosis was 3.0 years (interquartile range $0.0-11.0$ ). In total, 85 patients had previous treatment. For 35 (38.9\%), disease worsening during puberty was reported in medical records.

\section{Primary outcome}

Altogether, 41 (45.6\%) patients were LFU during HCT. Table 2 shows the characteristics of patients by LFU status. Age at diagnosis was significantly higher in patients LFU than not LFU (9.0 vs 2.0 years, $p=0.038$ ). The groups did not differ in age, sex, age of onset of follow-up in the hospital site, vascular malformation type, previous treatment of the malformation, frequency of physician's visits and need to change hospital site (from pediatric department to adult department).

\section{Health care consumption}

Table 3 displays the health care consumption by age during HCT for patients during follow-up. Scheduled consultations were from 0 to 10 per year for each age from pre-transition (age 13 years) to 19 years, with no increase in frequency during follow-up. Unscheduled hospitalization and admission to the emergency department ranged from 0 to 2 and 0 to 3 per year, respectively, for each age and were similar between age ranges.

\section{Modalities of HCT in participating French departments}

Among the 7 French tertiary centers that participated to the study, health providers were the same for children and adults followed up for SVMs in 6 centers and different in one. In 5 centers, adult and pediatric consultations took place at the same hospital site, and for 2 centers, patients had to change hospitals (from a specific pediatric one to an adult one) during the HCT. One center had a professional HCT coordinator and one center offered support groups or therapeutic workshops. The center with the HCT coordinator had similar results than the centers without HCT regarding number of loss to follow up ( $n=9 / 14$ patients LFU vs $n=32 / 76$ patients LFU).

\section{Patients' perceptions of the transition process}

Among all 90 patients, 47 completed the questionnaire (52.2\% response rate): 14 were LFU from the hospital center $(29.8 \%)$, and 33 were still followed up (70.2\%) (Fig. 1). The characteristics of responding patients are in 
Table 1 Characteristics of patients included

\begin{tabular}{|c|c|c|}
\hline & Missing data & $\mathrm{N}=90$ \\
\hline \multicolumn{3}{|l|}{ Demographic characteristics } \\
\hline Age, years & 2 & $21.0[20.0-22.25]$ \\
\hline Female sex & 0 & $51(56.7)$ \\
\hline \multicolumn{3}{|l|}{ Clinical features of vascular malformation } \\
\hline Vascular malformation type & 0 & \\
\hline Simple venous malformation & & $38(42.2)$ \\
\hline Simple lymphatic malformation & & $12(13.4)$ \\
\hline Simple arteriovenous malformation & & $9(10.0)$ \\
\hline Combined malformation (capillary/venous/lymphatic) & & $20(22.2)$ \\
\hline Vascular malformation associated with other anomalies & & $11(12.2)$ \\
\hline Location* ${ }^{*}$ & 1 & \\
\hline Head and neck/tongue & & $30(33.3)$ \\
\hline Trunk/gluteal area & & $22(24.4)$ \\
\hline Upper limb & & $16(17.8)$ \\
\hline Lower limb & & $36(40.0)$ \\
\hline Age at diagnosis & 10 & $3.0[0.0-11.0]$ \\
\hline Treatment of malformation* & 0 & \\
\hline Therapeutic abstention & & $5(5.6)$ \\
\hline Sclerotherapy/embolization & & $42(46.7)$ \\
\hline Drugs & & $34(37.8)$ \\
\hline Physical treatment (bandages, drainage, laser) & & $31(34.4)$ \\
\hline Surgery & & $44(48.9)$ \\
\hline \multicolumn{3}{|l|}{ Medical data puberty } \\
\hline Age at first period (for women only) & 7 & $13.0[12.0-14.0]$ \\
\hline Age at growth spurt & 65 & $13.0[12.0-14.0]$ \\
\hline Aggravation of the malformation in puberty (reported in the medical record) & 7 & $35(38.9)$ \\
\hline Aggravation of the malformation in puberty (reported by the patient) & 43 & $35(74.5)$ \\
\hline
\end{tabular}

Results are $\mathrm{n}$ (\%) for categorical variables and median [interquartile range] for quantitative variables

*A patient may have several characteristics

Table 4 . The median age of the responders was 21.0 years (interquartile range 20-22.0), 29 (61.7\%) were females (i.e., male/female ratio 1:1.6); 36 (76.6\%) were in college and $6(12.8 \%)$ had a professional activity. LFU and nonLFU patients did not differ in change of city for studies, discomfort linked to the malformation during adolescence and rate of patients who wanted to interrupt their follow-up during adolescence. Most patients were satisfied with their care $(n=31,86.1 \%$; missing data for 11 patients), with no difference between LFU and non-LFU groups. However, a lack of psychological support was reported (only 5 patients who responded to the questionnaire had been followed by a psychologist).

\section{Discussion}

To our knowledge, this is the first study to describe the HCT process in patients with SVMs. Among 90 patients included, $41(45.6 \%)$ were LFU during transition period. The change in hospital site (from pediatric to adult department) during the transition was not associated with increased frequency of LFU. Age of diagnosis of SVMs was significantly higher for patients LFU than non-LFU $(p=0.038)$.

There are many challenges inherent in the transition process from pediatric to adult care. This critical period takes place during adolescence, which is associated with physical and psychosocial changes, with a risk of SVM worsening, as reported for $39 \%$ of our patients. As a consequence, we could have expected an increased number of consultations and a low rate of LFU, but our study highlights a high rate of LFU (45.6\%). This could be explained by several factors: lack of curative treatments [16-18], prevalence of the disease, overloaded school schedules, follow-up fatigue in adolescents, or opposition to parents, for example. Indeed, in more common conditions (HIV and type 1 diabetes), the LFU rate is lower ( $19.8 \%$ and $8.6 \%$, respectively) and could be explained by the long-term treatment $[19,20]$ and because these are 


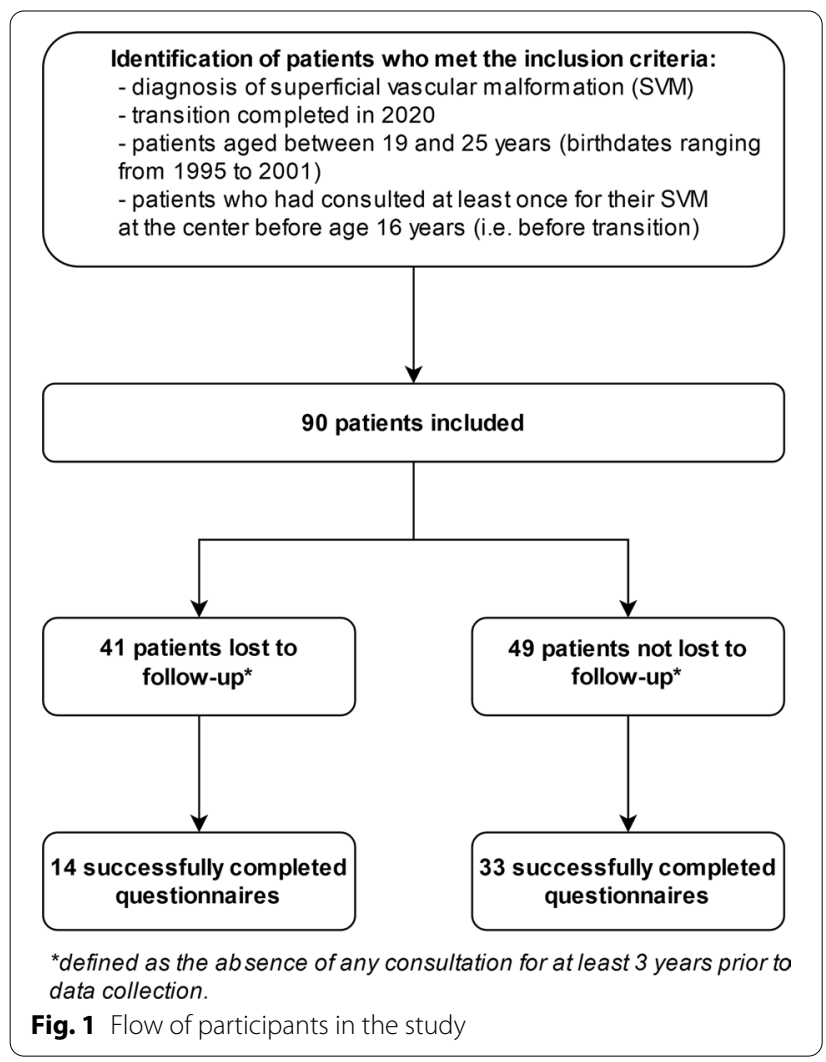

life-threatening diseases. Recently, sirolimus, a mammalian target of rapamycin inhibitor, has been increasingly used for complicated vascular malformations [21], and the targeted PIK3CA inhibitor alpelisib (BYL719) was recently administered with significant clinical benefit in SVMs in the PIK3CA-related overgrowth spectrum [22]. The prospect of new effective drugs for VMs could help reduce the number of LFU.

In our study, early diagnosis was associated with decreased risk of LFU. We can assume that when the diagnosis is early, the child's and parents' confidence in the medical team and therefore adherence to followup is better. Also, more extensive and therefore more troublesome SVMs may lead parents to consult earlier. This finding might be linked to the following: (1) patients with regular appointments during childhood might continue these into adulthood and (2) patients with a late first appointment probably have a less serious form that does not require treatment and for which regular follow-up is not required. Furthermore, we highlight that a transition coordinator was present in only one of the 7 centers. For other chronic conditions, the presence of a transition coordinator, who helps coordinate patient intake and follow-up as well as answers questions/concerns that the patient or family may have, seems an important element for the success of the process [23-25]. Contrary to diabetes, for example, SVMs are rare chronic conditions, and therefore a small number of patients receive treatment in each center. The implementation of transition protocols for small numbers of patients can be more difficult.

In our study, consumption of scheduled care from pre-transition (age 13 years) to 19 years was higher than unscheduled care. Rates of scheduled consultations seem similar to data from a Canadian study finding $44.3 \%$ of patients with non-complex chronic conditions consulting a specialist in the 2 years after HCT [26]. Rates of hospitalizations were higher than in this study, which found a rate of $6.3 \%$ of hospitalizations in the 2 years after HCT. In our study, consumption of unscheduled care was very low, with very few admissions to the emergency department or unplanned hospitalizations. In the previously mentioned study [26], rates of admissions to the emergency department were much higher: $45.9 \%$ of patients admitted in the 2 years after $\mathrm{HCT}$.

The survey part of our study highlighted an important psychological impact of the SVM as reported by the patient $(42.5 \%$ of respondents were very embarrassed or annoyed by the malformation). The satisfaction with psychological care by their doctor was low. Very few patients had a follow-up by a psychologist (10.6\%). Rates of psychological follow-up during this period were higher with other pathologies such as tuberous sclerosis complex (35.0\%) [27].

We did not evaluate adolescent medicine, including adolescent sexual and reproductive health, drug and alcohol use and abuse, smoking etc. in our study. Physicians should provide, during and after $\mathrm{HCT}$, teaching and counseling in these areas, especially for patients with a chronic condition with potential psychological impact [28].

\section{Limitations}

Our study may be underpowered because of the small sample size $(\mathrm{N}=90)$, which is explained by the rarity of SVMs and the small number of centers included $(n=7)$. Second, the number of patients LFU might be overestimated, if the patient moved and was followed up in a hospital that did not participate in the study. Moreover, our data collection may have been incomplete because we did not have access to the care consumption of patients outside the center (attending physician, emergency room or dermatology department in another hospital). Last, the age of HCT in France is 15 years and 3 months, younger than in the US at 18 years of age. Results may vary for different ages of transition. 
Table 2 Patient characteristics by their loss to follow-up status

\begin{tabular}{|c|c|c|c|c|}
\hline & Missing data & Lost to follow-up ( $\mathrm{N}=41)$ & $\begin{array}{l}\text { Not lost to } \\
\text { follow-up }(\mathrm{N}=49)\end{array}$ & $p$ value \\
\hline \multicolumn{5}{|l|}{ Demographic characteristics } \\
\hline Age, years & 2 & $21.0[20.0-22.25]$ & $21.0[20.0-22.25]$ & 0.42 \\
\hline Female sex & 0 & $25(61.0)$ & $26(53.1)$ & 0.28 \\
\hline \multicolumn{5}{|l|}{ Clinical features of vascular malformation } \\
\hline Vascular malformation type & 1 & & & 0.059 \\
\hline Simple venous malformation & & $23(56.1)$ & 15 (30.6) & \\
\hline Simple lymphatic malformation & & $7(17.1)$ & $6(10.2)$ & \\
\hline Simple arteriovenous malformation & & $2(4.9)$ & $7(14.3)$ & \\
\hline Combined malformation (capillary/venous/lymphatic) & & $6(14.6)$ & $14(28.6)$ & \\
\hline Syndromic malformation & & $3(7.3)$ & $8(16.3)$ & \\
\hline Location* & 1 & & & 0.53 \\
\hline Head and neck/tongue & & $10(24.4)$ & $20(40.8)$ & \\
\hline Trunk/gluteal area & & $10(24.4)$ & $12(24.5)$ & \\
\hline Upper limb & & $8(19.5)$ & $8(16.3)$ & \\
\hline Lower limb & & $18(43.9)$ & $18(36.7)$ & \\
\hline Age at diagnosis & 10 & $9.0[0.0-13.0]$ & $2.0[0.0-6.5]$ & 0.038 \\
\hline Previous treatment of malformation* & 0 & & & 0.055 \\
\hline Therapeutic abstention & & $4(9.8)$ & $1(2.0)$ & \\
\hline Sclerotherapy/embolization & & $18(43.9)$ & $24(49.0)$ & \\
\hline General drug treatment & & $7(17.1)$ & $27(55.0)$ & \\
\hline Physical treatment (bandages, drainage, laser) & & $13(31.7)$ & $18(36.7)$ & \\
\hline Surgery & & $14(34.2)$ & $30(61.2)$ & \\
\hline \multicolumn{5}{|l|}{ Follow-up procedures in the center } \\
\hline Age at onset of follow-up in the site & 2 & $13.0[9.0-14.0]$ & $9.0[3.5-13.0]$ & 0.07 \\
\hline Type of site & 0 & & & 0.71 \\
\hline Pediatric site & & $30(73.2)$ & $38(77.5)$ & \\
\hline Adult site & & $1(2.4)$ & $0(0.0)$ & \\
\hline Mixed site & & $10(24.4)$ & $11(22.5)$ & \\
\hline $\begin{array}{l}\text { Transition/change of site during follow-up (from pediatric to } \\
\text { adult department) }\end{array}$ & 1 & $9(22.5)$ & $14(28.6)$ & 0.23 \\
\hline Age at change of site & 2 & $17.0[16.0-16.5]$ & $16.0[14.5-16.5]$ & 0.09 \\
\hline Average number of consultations ${ }^{\dagger}$ & 7 & & & 0.08 \\
\hline$\leq 1$ time per year & & $11(26.8)$ & $25(51.0)$ & \\
\hline$>1$ time per year & & $30(73.2)$ & $24(49.0)$ & \\
\hline
\end{tabular}

Significance of bold: $p<0.05$ was considered statistically significant

Results are $\mathrm{n}(\%)$ for categorical variables and median [interquartile range] for quantitative variables

*A patient may have several characteristics

${ }^{\dagger}$ Mean number of consultations per year corresponding to the total number of consultations/number of years of follow-up

\section{Conclusions}

For young people with SVMs, HCT is a crucial period with the hormonal and psychological changes of adolescence and the potential change of hospital. Early diagnosis and follow-up, associated with psychological care and periodic physician visits, was associated with less LFU during and after the HCT. Evaluating HCT with measurable factors to be able to improve practice is an ambitious but necessary goal in rare chronic diseases.

\section{Methods}

\section{Study design and setting}

We conducted a cross-sectional multicenter study in patients with SVMs. Seven French centers involved in the network of the reference centers for vascular anomalies participated: departments of dermatology/ 
Table 3 Health care consumption during follow-up and health care transition by age range (from pre-transition [age 13 years] to 19 years)

\begin{tabular}{|c|c|c|c|c|c|c|c|}
\hline & Missing data & $13-14$ years & $14-15$ years & $15-16$ years & $16-17$ years & $17-18$ years & $18-19$ years \\
\hline Patients with $>1$ scheduled consultations & 5 & 13/70 (18.6\%) & $27 / 76(35.5 \%)$ & $16 / 70(22.9 \%)$ & $19 / 66(22.8 \%)$ & $24 / 62(38.7 \%)$ & $23 / 56(41.1 \%)$ \\
\hline $\begin{array}{l}\text { Number of scheduled consultations, } \\
\text { median [range] }\end{array}$ & 5 & $0[0-6]$ & $0[0-5]$ & $1[0-6]$ & $1[0-5]$ & $1[0-10]$ & $1[0-10]$ \\
\hline $\begin{array}{l}\text { Patients with } \geq 1 \text { emergency department } \\
\text { visit(s) }\end{array}$ & 5 & $0 / 70(0.0 \%)$ & $4 / 76(5.3 \%)$ & $1 / 71(1.4 \%)$ & $1 / 67(1.5 \%)$ & $3 / 63(4.8 \%)$ & $2 / 57(3.5 \%)$ \\
\hline $\begin{array}{l}\text { Number of emergency department } \\
\text { visits, median [range] }\end{array}$ & 5 & $0[0-0]$ & $0[0-2]$ & $0[0-3]$ & $0[0-1]$ & $0[0-1]$ & $0[0-2]$ \\
\hline $\begin{array}{l}\text { Patients with } \geq 1 \text { unscheduled } \\
\text { hospitalization(s) }\end{array}$ & 5 & $0 / 72(0.0 \%)$ & $2 / 78(2.6 \%)$ & $1 / 73(1.4 \%)$ & $0 / 69(0.0 \%)$ & $2 / 65(3.1 \%)$ & $1 / 59(1.7 \%)$ \\
\hline $\begin{array}{l}\text { Number of unscheduled hospitaliza- } \\
\text { tions, median [range] }\end{array}$ & 5 & $0[0-0]$ & $0[0-2]$ & $0[0-2]$ & $0[0-1]$ & $0[0-1]$ & $0[0-2]$ \\
\hline
\end{tabular}

Results are number/number (\%) of patients at risk for the period and median [range]

We defined health care transition-age as ranging from 13 to 19 years old, because at 13 years old, the transition to adult care has not yet begun and at 19 years, this process is considered completed

pediatric dermatology of Angers, Dijon, Marseille, Nice, Paris-Necker, Toulouse and Tours.

\section{Participants}

We included all patients followed up for an SVM who had completed the transition period in 2020 (i.e., age 19-25 years old [birthdates from 1995 and 2001]). Criteria for eligibility included patients consulting at least once for their SVM at the center before age 16 years (i.e., patients who had not completed transition process) so we could investigate the transition period.

Patients all had an SVM (lymphatic, venous or arteriovenous malformations) confirmed by imaging (ultrasonography, CT-scan, or MRI) that did not have curative treatment. The SVM was simple, combined or associated with other anomalies, whatever the topography. We excluded patients with simple capillary malformations, because this condition might not always require systematic follow-up, and those with incomplete medical records.

\section{Definition of HCT age}

There is no precise definition of HCT age, which varies in the literature [10] and depends on several factors, mostly the country hospital structure policies. In France, the age of transfer (physical change of hospital site from pediatric to adult department) is 15 years and 3 months. We assume that the adolescence period includes a "pre-transition" process, ranging from approximately age 13-16 years, then a transition process (including transfer), which starts from age 16 years and is usually completed at age 19 years and is followed by a post-transition period. Therefore, we decided to include patients who consulted at least once for their superficial vascular malformation (SVM) at the hospital center before age 16 years in order to include patients who had not completed their transition.

\section{Data collected}

We collected the following data from clinical records: demographic characteristics (age, sex), characteristics of the SVM (type, localization, simple or combined), history (age of diagnosis, previous treatment, effect of puberty on the SVM), current follow-up and change of hospital site during follow-up, and care consumption (last pediatric/ adult care; number of physician visits, hospitalizations and emergency department admissions from pre-transition (age 13 years) to 19 years.

Included patients were asked to complete a standardized questionnaire. To optimize the response rate, patients who did not complete the questionnaire were contacted by telephone. The questionnaire included 32 items respecting anonymity: (1) socio-professional data (age, sex, marital status, professional status, change of city for studies and education level); (2) data on the period of adolescence (first menstrual period, age of growth spurt, embarrassment or complex due to malformation, aggravation of the malformation during puberty); (3) data on medical care during the transition from pediatric to adult health care (change of hospital site during transition, desire to stop the follow-up, psychological follow-up, hospital follow-up); (4) data on satisfaction of the patient with the follow-up during adolescence/transition (satisfaction with follow-up and regularity of appointments); and (5) data for the current follow-up (embarrassment or complex due to malformation). No data on LFU status were collected from the questionnaires. Finally, a form was completed by the 
Table 4 Characteristics of responders to the survey regarding their loss to follow-up status

\begin{tabular}{|c|c|c|c|c|c|}
\hline & Missing data & Total $(\mathrm{N}=47)$ & Lost to follow-up (N=14) & $\begin{array}{l}\text { Not lost to } \\
\text { follow-up ( } N=33 \text { ) }\end{array}$ & $p$ value \\
\hline \multicolumn{6}{|l|}{ Demographic characteristics } \\
\hline Age, years & 0 & $21.0[20.0-22.0]$ & $20.5[20.0-22.0]$ & $21.0[20.0-22.0]$ & 0.58 \\
\hline Female sex & 0 & $29(61.7)$ & $13(92.9)$ & $16(48.5)$ & 0.01 \\
\hline Professional status & & & & & 0.19 \\
\hline High school & & $1(2.1)$ & $0(0.0)$ & $1(3.0)$ & \\
\hline College & & $36(76.6)$ & $10(71.4)$ & $26(78.8)$ & \\
\hline Professional activity & & $6(12.8)$ & $1(7.1)$ & $5(15.2)$ & \\
\hline Not working because of disability & & $2(4.3)$ & $2(14.3)$ & $0(0.0)$ & \\
\hline Not working & & $2(4.3)$ & $1(7.1)$ & $1(3.0)$ & \\
\hline Education level & 1 & & & & 0.97 \\
\hline Primary/high school education & & $25(54.3)$ & $7(53.9)$ & $18(54.5)$ & \\
\hline College/university education & & $21(45.7)$ & $6(46.1)$ & $15(45.5)$ & \\
\hline Marital status & 0 & & & & $>0.99$ \\
\hline Single & & $42(89.4)$ & $13(92.9)$ & $29(87.9)$ & \\
\hline Married/common law & & $5(10.6)$ & $1(7.1)$ & $4(12.1)$ & \\
\hline Change of city for studies & 0 & $25(53.2)$ & $7(50.0)$ & $18(54.5)$ & $>0.99$ \\
\hline \multicolumn{6}{|l|}{ Data on the period of adolescence/transition } \\
\hline Embarrassment or complex due to malformation & 1 & & & & $>0.99$ \\
\hline Yes, absolutely & & $20(42.5)$ & $6(46.2)$ & $14(42.4)$ & \\
\hline Yes, rather & & $10(21.7)$ & $3(23.0)$ & $7(21.2)$ & \\
\hline No, not really & & $8(17.4)$ & $2(15.4)$ & $5(15.2)$ & \\
\hline Not at all & & $8(17.4)$ & $2(15.4)$ & $6(18.2)$ & \\
\hline Want to stop follow-up & 1 & & & & 0.72 \\
\hline Yes, absolutely & & $7(15.2)$ & $3(23.1)$ & $4(12.1)$ & \\
\hline Yes, rather & & $7(15.2)$ & $2(15.4)$ & $5(15.2)$ & \\
\hline No, not really & & $9(19.6)$ & $3(23.1)$ & $6(18.2)$ & \\
\hline Not at all & & $23(50.0)$ & $5(38.4)$ & $18(54.5)$ & \\
\hline Patients satisfied with follow-up & 11 & $31(86.1)$ & $8(88.9)$ & $23(85.2)$ & $>0.99$ \\
\hline Regularity of appointments & 13 & & & & $>0.99$ \\
\hline Adapted & & $25(75.7)$ & $6(75.0)$ & $19(79.1)$ & \\
\hline Not enough & & $6(15.2)$ & $1(12.5)$ & $5(20.8)$ & \\
\hline Too frequent & & $3(9.1)$ & $1(12.5)$ & $2(8.3)$ & \\
\hline Psychological follow-up & 1 & $5(10.6)$ & $1(7.1)$ & $4(12.5)$ & $>0.99$ \\
\hline Change of site during monitoring & 1 & $22(47.8)$ & $9(69.3)$ & $13(40.6)$ & 0.20 \\
\hline Age at change of site & 2 & $16.0[16.0-17.5]$ & $16.0[15.5-17.5]$ & $16.0[16.0-17.8]$ & \\
\hline Decision to change site & 3 & & & & $>0.99$ \\
\hline Good time & & $16(84.2)$ & $7(87.5)$ & $9(81.8)$ & \\
\hline Too soon & & $3(15.8)$ & $1(12.5)$ & $2(18.2)$ & \\
\hline Too late & & $0(0.0)$ & $0(0.0)$ & $0(0.0)$ & \\
\hline Change in support & 0 & & & & 0.29 \\
\hline Yes, absolutely & & $3(13.6)$ & $1(11.1)$ & $2(15.4)$ & \\
\hline Yes, rather & & $7(31.8)$ & $5(55.6)$ & $2(15.4)$ & \\
\hline No, not really & & $7(31.8)$ & $2(22.2)$ & $5(38.4)$ & \\
\hline Not at all & & $5(22.7)$ & $1(11.1)$ & $4(30.8)$ & \\
\hline Data for the current (post-transition) period & & & & & 0.66 \\
\hline Embarrassed or annoyed by the malformation & 0 & & & & \\
\hline Yes, absolutely & & $12(25.5)$ & $3(21.4)$ & $9(27.3)$ & \\
\hline Yes, rather & & $9(19.1)$ & $2(14.3)$ & $7(21.2)$ & \\
\hline No, not really & & $8(17.0)$ & $4(28.6)$ & $4(12.1)$ & \\
\hline Not at all & & $18(38.3)$ & $5(35.7)$ & $13(39.4)$ & \\
\hline
\end{tabular}

Significance of bold: $p<0.05$ was considered statistically significant

Results are $\mathrm{n}(\%)$ for categorical variables and mean $\pm \mathrm{SD}$ or median [interquartile range] for quantitative variables 
investigator of each center to collect data on the center's practices regarding modalities of HCT.

\section{Endpoints}

The primary outcome was the proportion of patients who were LFU, defined as lack of any consultation for at least 3 years in the hospital site participating in the study before data collection. These data were collected from clinical records. Secondary outcomes were (1) the health care consumption, assessed by the number of hospitalizations, admissions to the emergency department and physician's visit from pre-transition (age 13 years) to 19 years; (2) patients' perception of HCT (by the questionnaire); and (3) modalities of HCT in French tertiary centers.

\section{Statistical analysis}

Descriptive data are presented as median (interquartile range) or range for quantitative data and frequency (percentage) for categorical data. We used no methods to handle missing data. Means were compared by Student $t$ test and Wilcoxon sum rank test when necessary. Frequencies were compared by chi-square test and Fisher's exact test as appropriate. No sensitivity analysis was performed. Statistical analyses involved using R v4.0.2. Twosided $p<0.05$ was considered statistically significant.

\section{Abbreviations}

HCT: Health care transition; LFU: Lost to follow-up; SVM: Superficial vascular malformation.

\section{Acknowledgements}

We are indebted to Mrs. Emiliène Edée from the Department of Dermatology, University Hospital Centre (CHU) Tours; Jéhanne MARTEL from the Department of Dermatology, University Hospital Centre (CHU) Dijon and Mr Jocelyn Rapp from the Department of Dermatology, University Hospital Centre (CHU) Nice for their technical help.

\section{Authors' contributions}

CV conceptualized and designed the study, collected, analyzed, and interpreted data, drafted the initial manuscript, and reviewed and revised the manuscript. SL conceptualized and designed the study, conducted statistical analysis, drafted the initial manuscript, and reviewed and revised the manuscript. AM conceptualized and designed the study, supervised the study, drafted the initial manuscript, and reviewed and revised the manuscript. OB, CC, JMH, NS, SM, PV, DH, ALT conceptualized and designed the study, collected data, and critically reviewed the manuscript for important intellectual content. All authors read and approved the final manuscript.

\section{Funding}

None.

\section{Availability of data and materials}

The datasets used and/or analysed during the current study are available from the corresponding author on reasonable request.

\section{Declarations}

Ethics approval and consent to participate

The study was approved by the institutional review board of the University Hospital Center of Tours and received approval from the Commission Nationale de l'Informatique et des Libertés. Patients received written information.

\section{Consent for publication}

Not available.

\section{Competing interests}

The authors declare that they have no competing interests.

\section{Author details}

${ }^{1}$ Department of Dermatology and Reference Center for Rare Diseases and Vascular Malformations (MAGEC), CHRU Tours, Avenue de La République, 37044 Tours Cedex 9, France. ${ }^{2}$ Department of Dermatology and Reference Center for Genodermatoses and Rare Skin Diseases (MAGEC), Necker-Enfants Malades University Hospital, APHP5, Paris, France. ${ }^{3}$ Imagine Institute, Paris University, Necker-Enfants Malades University Hospital, APHP5, Paris, France. ${ }^{4}$ Department of Dermatology, University Hospital Center of Nice, Nice, France. ${ }^{5}$ Department of Dermatology, University Hospital Center of Toulouse, Toulouse, France. ${ }^{6}$ Department of Dermatology, University Hospital Center of Angers, Angers, France. ${ }^{7}$ Department of Dermatology, University Hospital Center of Marseille, 13885 Marseille Cedex 5, France. ${ }^{8}$ Department of Dermatology, University Hospital Center of Dijon, Dijon, France. ${ }^{9}$ Department of Neuroradiology and Interventional Radiology, University Hospital Center of Tours, Tours, France. ${ }^{10}$ Department of Pediatric Surgery, University Hospital Center of Tours, Tours, France. ${ }^{11}$ Universities of Tours and Nantes, INSERM 1246-SPHERE, 37000 Tours, France.

Received: 20 March 2021 Accepted: 19 July 2021

Published online: 06 August 2021

\section{References}

1. Tasnádi G. Epidemiology and etiology of congenital vascular malformations. Semin Vasc Surg. 1993;6:200-3.

2. Brouillard P, Vikkula M. Genetic causes of vascular malformations. Hum Mol Genet. 2007;16 Spec No. 2:R140-9.

3. Keppler-Noreuil KM, Rios JJ, Parker VE, Semple RK, Lindhurst MJ, Sapp JC, et al. PIK3CA-related overgrowth spectrum (PROS): diagnostic and testing eligibility criteria, differential diagnosis, and evaluation. Am J Med Genet A. 2015;167A:287-95.

4. Wassef M, Blei F, Adams D, Alomari A, Baselga E, Berenstein A, et al. Vascular anomalies classification: recommendations from the International Society for the Study of Vascular Anomalies. Pediatrics. 2015;136:e203-14.

5. Guillet A, Connault J, Perrot P, Perret C, Herbreteau D, Berton M, et al. Early symptoms and long-term clinical outcomes of distal limb's cutaneous arterio-venous malformations: a retrospective multicentre study of 19 adult patients. J Eur Acad Dermatol Venereol. 2016;30:36-40.

6. Hassanein AH, Mulliken JB, Fishman SJ, Quatrano NA, Zurakowski D, Greene AK. Lymphatic malformation: risk of progression during childhood and adolescence. J Craniofac Surg. 2012;23:149-52.

7. Enjolras O, Logeart I, Gelbert F, Lemarchand-Venencie F, Reizine D, Guichard JP, et al. Arteriovenous malformations: a study of 200 cases. Ann Dermatol Venereol. 2000;127:17-22.

8. Pappas DC, Persky MS, Berenstein A. Evaluation and treatment of head and neck venous vascular valformations. Ear Nose Throat J. 1998;77:914-22.

9. Campagna BR, Weatherley K, Shemesh E, Annunziato RA. Adherence to medication during transition to adult services. Paediatr Drugs. 2020;22:501-9.

10. Yassaee A, Hale D, Armitage A, Viner R. The impact of age of transfer on outcomes in the transition from pediatric to adult health systems: a systematic review of reviews. J Adolesc Health. 2019;64:709-20.

11. Society for Adolescent Health and Medicine. Transition to adulthood for youth with chronic conditions and special health care needs. J Adolesc Health. 2020;66:631-4. 
12. Blum RW, Garell D, Hodgman CH, Jorissen TW, Okinow NA, Orr DP, et al. Transition from child-centered to adult health-care systems for adolescents with chronic conditions: a position paper of the Society for Adolescent Medicine. J Adolesc Health. 1993;14:570-6.

13. Agwu AL, Lee L, Fleishman JA, Voss C, Yehia BR, Althoff KN, et al. Aging and loss to follow-up among youth living with human immunodeficiency virus in the HIV research network. J Adolesc Health. 2015;56:345-51.

14. Lotstein DS, Seid M, Klingensmith G, Case D, Lawrence JM, Pihoker C, et al. Transition from pediatric to adult care for youth diagnosed with type 1 diabetes in adolescence. Pediatrics. 2013;131:e1062-1070.

15. Perez VA, Morel KD, Garzon MC, Lauren CT, Levin LE. Review of transition of care literature: epidermolysis bullosa, a paradigm for patients with complex dermatologic conditions. J Am Acad Dermatol. 2020;S0190-9622(20):31182-8.

16. Hage AN, Chick JFB, Srinivasa RN, Bundy JJ, Chauhan NR, Acord M, et al. Treatment of venous malformations: the data, where we are, and how it is done. Tech Vasc Interv Radiol. 2018;21:45-54.

17. Elluru RG, Balakrishnan K, Padua HM. Lymphatic malformations: diagnosis and management. Semin Pediatr Surg. 2014;23:178-85.

18. Cox JA, Bartlett E, Lee El. Vascular malformations: a review. Semin Plast Surg. 2014;28:58-63.

19. Kranzer K, Bradley J, Musaazi J, Nyathi M, Gunguwo H, Ndebele W, et al. Loss to follow-up among children and adolescents growing up with HIV infection: age really matters. J Int AIDS Soc. 2017;20:21737.

20. Farrell K, Fernandez R, Salamonson Y, Griffiths R, Holmes-Walker DJ. Health outcomes for youth with type 1 diabetes at 18 months and 30 months post transition from pediatric to adult care. Diabetes Res Clin Pract. 2018;139:163-9.

21. Sandbank S, Molho-Pessach V, Farkas A, Barzilai A, Greenberger S. Oral and topical sirolimus for vascular anomalies: a multicentre study and review. Acta Derm Venereol. 2019;99:990-6.
22. Venot Q, Blanc T, Rabia SH, Berteloot L, Ladraa S, Duong JP, et al. Targeted therapy in patients with PIK3CA-related overgrowth syndrome. Nature. 2018;558:540-6.

23. Schultz AT, Smaldone A. Components of interventions that improve transitions to adult care for adolescents with type 1 diabetes. J Adolesc Health. 2017;60:133-46.

24. Gray WN, Holbrook E, Dykes D, Morgan PJ, Saeed SA, Denson LA. Improving IBD transition, self-management, and disease outcomes with an inclinic transition coordinator. J Pediatr Gastroenterol Nutr. 2019:69:194-9.

25. Spaic T, Robinson T, Goldbloom E, Gallego P, Hramiak I, Lawson ML, et al. Closing the gap: results of the multicenter Canadian randomized controlled trial of structured transition in young adults with type 1 diabetes. Diabetes Care. 2019;42:1018-26.

26. Cohen E, Gandhi S, Toulany A, Moore C, Fu L, Orkin J, et al. Health care use during transfer to adult care among youth with chronic conditions. Pediatrics. 2016;137:e20152734.

27. Bar C, Ghobeira R, Azzi R, Ville D, Riquet A, Touraine R, et al. Experience of follow-up, quality of life, and transition from pediatric to adult healthcare of patients with tuberous sclerosis complex. Epilepsy Behav. 2019;96:23-7.

28. Sable C, Foster E, Uzark K, Bjornsen K, Canobbio MM, Connolly HM, et al Best practices in managing transition to adulthood for adolescents with congenital heart disease: the transition process and medical and psychosocial issues: a scientific statement from the American Heart Association. Circulation. 2011;123:1454-85.

\section{Publisher's Note}

Springer Nature remains neutral with regard to jurisdictional claims in published maps and institutional affiliations.
Ready to submit your research? Choose BMC and benefit from:

- fast, convenient online submission

- thorough peer review by experienced researchers in your field

- rapid publication on acceptance

- support for research data, including large and complex data types

- gold Open Access which fosters wider collaboration and increased citations

- maximum visibility for your research: over $100 \mathrm{M}$ website views per year

At BMC, research is always in progress.

Learn more biomedcentral.com/submissions 